\title{
A. BORTHAKUR \\ Joint distribution of the number of customers in the queue and the number of batches served at time $t$ within a busy period
}

Revue française d'automatique, d'informatique et de recherche opérationnelle. Recherche opérationnelle, tome 15, nº 3 (1981), p. 271-277.

<http://www.numdam.org/item?id=RO_1981_15_3_271_0>

(C) AFCET, 1981, tous droits réservés.

L'accès aux archives de la revue « Revue française d'automatique, d'informatique et de recherche opérationnelle. Recherche opérationnelle » implique l'accord avec les conditions générales d'utilisation (http://www.numdam.org/ legal.php). Toute utilisation commerciale ou impression systématique est constitutive d'une infraction pénale. Toute copie ou impression de ce fichier doit contenir la présente mention de copyright.

\section{Numdam}




\title{
JOINT DISTRIBUTION OF THE NUMBER OF CUSTOMERS IN THE QUEUE AND THE NUMBER OF BATCHES SERVED AT TIME $t$ WITHIN A BUSY PERIOD (*)
}

\author{
by A. BORTHAKur $\left({ }^{1}\right)$
}

\begin{abstract}
This paper deals with a bulk queueing system with Poisson input and general service time under the service policy that a batch will contain not less than " $a$ " and not more than " $b$ " units. The object of this note is to obtain the joint distribution of the number of customers in the queue at time " $t$ " and the number of batches served in $(0, t)$ for the first (or a particular) busy period of such a bulk queue. Some earlier results are also derived as special cases of our present result.

Keywords: bulk queue, general bulk service rule, busy period.

Résumé. - On considère ici un modèle du type $M / G / 1$ où les services se font par groupes d'unités tel que le quorum d'unités qui doivent être présentes pour qu'un service commence, soit «a ", et la capacité ou l'effectif maximal autorisé de service, soit «b». L'objet de cette note est d'obtenir la distribution jointe du nombre d'unités à la file au temps " $t$ " et du nombre de groupes servis en $(0, t)$ pendant la première "période occupée" (busy period). Des résultats déjà connus en sont derivés comme cas particuliers.
\end{abstract}

\section{INTRODUCTION}

Prabhu [3] obtained the joint distribution ( $j d)$ of the length of the busy period and the number of customers served during that busy period for the $\mathrm{M} / \mathrm{G} / 1$ queueing system. Later, Greenberg and Greenberg [2] considered the unrestricted $\mathrm{M} / \mathrm{M} / 1$ queue and obtained the $j d$ of the number of customers in the system at time $t$ and the number of customers served in the interval $(0, t)$. Recently, Scott $[4,5]$ has extended this result further and obtained the Laplace transform (L.T.) of the generating function $(g f)$ of the $j d$ of the number of customers in the system at time $t$, the number of customers already served and the number of busy periods completed in the interval $(0, t)$ for a $M / M / 1$ queue with limited waiting room and an unrestricted $M / G / 1$ queueing system. His results lead to the determination of a number of useful results.

(*) Received April 1980.

( $\left.{ }^{1}\right)$ Gauhati University, Department of Statistics, 781014 Assam, India.

R.A.I.R.O. Recherche operationnelle/Operations Research, 0399-0559/1981/271/ $\$ 5.00$

(C) AFCET-Bordas-Dunod 
The purpose of the note is to obtain, within the first or a particular busy period the L. $T$, of the $g$ for the $j d$ of the number of customers in the quene (excluding those in service) at the $t$ and the number of batches served in the in terval $(0, t)$ for an untestricted M/G/1 queue where customers arriving in groups are served in batches ander the general rule for bulk service.

We assume that customers arrive in gromps of variable size in accordance with a Poisson process with parameter $\lambda_{2} \lambda_{r} \Delta t\left(\sum_{z=1}^{\infty} c_{r}=1\right)$ is the first order probability that a group of size rartives in time $\Delta t$. The customen are served by a single server of capacity " $b$ " in batches of size $(k \mid a \leq k \leq b)$ under the "general rule" for bulk service. Ender this general wule the server starts service only when a minimum number of units " $a$ " is present in the queve. If the server is free and if the number of mits in the queue is " $a$ " or more but less than or equal to " $b$ ", the entire quete is taken for service and if the queue length is greater than $b$ then " $b$ " units are taken into service while others wat in the quete. The service time of each batch is assumed to have independent general distribution with density function $D(t)$ and is independent of batch size.

\section{EQUATHONS OF THE SYSTEM}

Define:

$P_{m, n}(x, t) d x \equiv$ probability that the server is busy, the number of customers waiting in the queue at time $t$ is $m$, the number of batches served during the interval $(0, t)$ is $n$ and a batch is boing served with elapsed service time lying betwen $x$ and $x+d x(m, n \geq 0)$;

$P_{m, n}(t)=$ ptobability that the server is busy, the number of customers waiting in the queue at the $t$ is $m$ and the number of batches served during the interval $(0, t)$ is $n(m, n \geq 0)$;

$Q_{r_{2},}(t)=$ probability that the systcm is idle, the number of customers wating in the queue at time $t$ is $r$ and the number of batches served in $(0, t)$ is $n(n \geq 0,0 \leq 7 \leq a-1)$

$f_{r}(t, n)=$ joint probability that the length of the (conditional) busy period ending with $r$ customers in the queve is $t$ and the number of batches served in its dutation is $n(n \geq 1,0 \leqq * \leq a-1)$.

Elementary probabitity reasoning leads to the following difference-differential equations for the frst (or a particular) busy period:

$$
(\partial f \partial x) P_{0, n}(x, t)+(\partial / \partial t) P_{0, n}(x, t)=-\left[\lambda_{t}+l(x)\right] P_{0, n}(x, t) \quad(n \geq 0)
$$


$(\partial / \partial x) P_{m, n}(x, t)+(\partial / \partial t) P_{m, n}(x, t)$

$$
\left.\begin{array}{c}
=-[\lambda+l(x)] P_{m, n}(x, t)+\sum_{i=1}^{m} \lambda c_{i} P_{m-i, n}(x, t) \quad(m \geqq 1, n \geqq 0) \\
f_{r}(t, n)=(d / d t) Q_{r, n}(t)=\int_{0}^{\infty} P_{r, n-1}(x, t) l(x) d x \\
(0 \leqq r \leqq a-1)
\end{array}\right\}
$$

where $l(x) d x$ is the first order conditional probability that the service will be completed in the interval $(x, x+d x)$ given that it has not been completed till time $x ; D(x)$ and $l(x)$ being connected by the relation:

$$
D(x)=l(x) \exp \left\{-\int_{0}^{x} l(y) d y\right\} .
$$

The boundary conditions are:

$$
\begin{gathered}
P_{m, 0}(0, t)=0 \quad(m \geqq 0), \\
P_{0, n}(0, t)=\sum_{r=a}^{b} \int_{0}^{\infty} P_{r, n-1}(x, t) l(x) d x \quad(n \geqq 1), \\
P_{m, n}(0, t)=\int_{0}^{\infty} P_{m+b, n-1}(x, t) l(x) d x \quad(m, n \geqq 1) .
\end{gathered}
$$

\section{SOLUTIONS OF THE EQUATIONS}

Let us assume that the time origin is the beginning of the service of a batch of size $(k \mid a \leqq k \leqq b)$ with zero customers in the waiting line, i. e.:

$$
P_{0,0}(x, 0)=\delta(x)
$$

Using the generating functions:

$$
\begin{gathered}
C(u)=\sum_{1}^{\infty} c_{i} u^{n}, \quad F_{r}(t, v)=\sum_{n=1}^{\infty} f_{r}(t, n) v^{n}, \\
P(t ; u, v)=\sum_{n=0}^{\infty} \sum_{m=0}^{\infty} P_{m, n}(t) u^{m} v^{n},
\end{gathered}
$$

and:

$$
P(x, t ; u, v)=\sum_{m=0}^{\infty} \sum_{n=0}^{\infty} P_{m, n}(x, t) u^{m} v^{m}
$$


it is easy to obtain from (1) through (2) and (4) through (6) that:

$$
\begin{aligned}
& (\partial / \partial x) P(x, t ; u, v)+(\partial / \partial t) P(x, t ; u, v) \\
& +[\lambda+l(x)-\lambda C(u)] P(x, t ; u, v)=0 \\
& \begin{aligned}
u^{b} P(0, t ; u, v)=v \int_{0}^{\infty} P(0, t ; u, v) l(x) d x \\
+v \sum_{n=0}^{\infty} v^{n} \sum_{r=a}^{b-1}\left(u^{b}-u^{r}\right) \int_{0}^{\infty} P_{r, n}(x, t) l(x) d x \\
-v \sum_{n=0}^{\infty} v^{n}\left\{\sum_{r=0}^{a-1} u^{r} \int_{0}^{\infty} P_{r, n}(x, t) l(x) d x\right\} .
\end{aligned}
\end{aligned}
$$

The solution of the Lagrangian type of equation given by (8) is:

$$
P(x, t ; u, v)=H(t-x ; u, v) \exp \{-N(x)-\lambda[1-C(u)] x\},
$$

where $N(x)=\int_{0}^{x} l(y) d y$ and $H(., u, v)$ is given by:

$$
\begin{gathered}
H(-y ; u, v)=\delta(y) \quad \text { for } \quad y>0 \\
H(t ; u, v)=P(0, t ; u, v) \quad \text { for } \quad t>0 .
\end{gathered}
$$

Let us now denote the L.T. of a function $f(t)$ by $\bar{f}(s)$. Thus, we find from (10) on using (7):

$$
\bar{P}(x, s ; u, v)=[1+\bar{P}(0, s ; u, v)] \exp \{-N(x)-x h(s, u)\},
$$

where $h(s, u)=s+\lambda-\lambda C(u)$.

Substituting (11) into the L.T. of (9) and using the L.T. of (3), we get, on simplification:

$$
1+\bar{P}(0, s ; u, v)=A(s ; u, v) /\left[u^{b}-v \bar{D}\{h(s, u)\}\right],
$$

where:

$A(s ; u, v)=u^{b}+v \sum_{n=0}^{\infty} v^{n} \sum_{r=a}^{b-1}\left(u^{b}-u^{r}\right) \int_{0}^{\infty} \bar{P}_{r, n}(x, s) l(x) d x-\sum_{r=0}^{a-1} u^{r} \bar{F}_{r}(s, v)$.

Now, since $1+\bar{P}(0, s ; u, v)$ converges in the region $|v| \leqq 1, \operatorname{Re}(s)>0$, the zeros of the denominator and numerator on the right hand side of (12) must coincide. Hence, following Rouche's theorem, we get that the zeros of (12) lying inside the unit circle $|u|=1$ must make the numerator vanish giving rise to $b$ 
equations $A\left(s ; u_{i}, v\right)=0,(i=1,2, \ldots, b)$. These $b$ equations when solved give the $b$ unknowns, viz., $\bar{F}_{r}(s, v),(r=0,1, \ldots, a-1)$;

$$
\sum_{n=0}^{\infty} \int_{0}^{\infty} \bar{P}_{r, n}(x, s) l(x) d x \quad(r=a, a+1, \ldots, b-1) .
$$

Thus $1+\bar{P}(0, s ; u, v)$ is completely known.

Hence, from (11) and (12), we find:

$$
\begin{aligned}
\bar{P}(s ; u, v)=\int_{0}^{\infty} \bar{P}(x, s ; u, v) d x & \\
= & {[(1-\bar{D}\{h(s, u)\}) / h(s, u)] } \\
& \times\left[A(s ; u, v) /\left(u^{b}-v \bar{D}\{h(s, u)\}\right] .\right.
\end{aligned}
$$

The equation (13) determines, in terms of L.T., the $g$ f of the $j d$ of the number of customers waiting in the queue at time $t$ and the number of batches served during the period $(0, t)$.

\section{PARTICULAR CASES}

I. If in equation (13) above, we let $v \rightarrow 1$, we get the L.T. of the $g f$ of the busy period process as:

$$
\begin{aligned}
\bar{P}(s ; u, 1)=[(1-\bar{D} & \{h(s, u)\}) / h(s, u)] \\
& \times\left[\left\{u^{b}-\sum_{r=a}^{b-1}\left(u^{b}-u^{r}\right) \int_{0}^{\infty} \bar{P}_{r}(x, s) l(x) d x\right.\right. \\
& \left.\left.-\sum_{r=0}^{a-1} u^{r} \bar{F}_{r}(s, 1)\right\} /\left(u^{b}-\bar{D}\{h(s, u)\}\right)\right],
\end{aligned}
$$

where:

$$
\bar{P}_{r}(x, s)=\sum_{n=0}^{\infty} P_{r, n}(x, s) \quad \text { and } \quad \bar{F}_{r}(s, 1)=\sum_{n=0}^{\infty} \bar{f}_{r}(s, n) \text {. }
$$

The above result agrees with that of Borthakur [1].

II. By letting $u \rightarrow 1$ in (13), we get the L:T. of the $g f$ of the number of batches served during the interval $(0, t)$. Thus we have:

$$
\bar{P}(s ; 1, v)=\left[1-\sum_{r=0}^{a-1} \bar{F}_{r}(s ; v)\right] /[(s+\mu)-v \mu] .
$$


It is important to note that this $g f$ is independent of batch size in which it occurs in service mechanism and input process.

III. Suppose arrival and service occur one by one and the servicing time of each unit is negative exponential with parameter $\mu$. In this case:

$$
\bar{P}(s ; u, v)=\left[u-\bar{F}_{0}(s, v)\right] /[u(s+\lambda-\lambda u+\mu)-v \mu] .
$$

On using the Rouche's theorem, $\vec{P}(s ; u, v)$ can be put in the form:

$$
\bar{P}(s ; u, v)=(1 / \lambda)\left[\alpha_{2}(s, v)-u\right]^{-1},
$$

where $\alpha_{i}(s, v), i=1.2\left(\alpha_{2}>\alpha_{1}\right)$ being the roots of the equation:

$$
\lambda u^{2}-(s+\lambda+\mu) u+v \mu=0
$$

are given by:

$$
\alpha_{i}(s, v)=[(s+\lambda+\mu) \pm \sqrt{(s+\lambda+\mu)-4 \lambda \mu v}] / 2 \lambda
$$

Now collecting the co-efficient of $u^{m} v^{m}$ from the expansion of $\bar{P}(s ; u, v)$, we find:

$$
\begin{aligned}
\bar{P}_{m, n}(s)=[(m+1)(m+2 n) ! / n !(m+n+1) !] \\
\times \lambda^{m+n} \mu^{n}(s+\lambda+\mu)^{-(m+2 n+1)}, \quad m, n \geqq 0 .
\end{aligned}
$$

The Laplace inverse of $\bar{P}_{m, n}(s)$ is:

$P_{m, n}(t)=[(m+1) / n !(m+n+1) !](\mu / \lambda)^{n} e^{-(\lambda+\mu) t}(\lambda t)^{m+2 n}, \quad m, n \geqq 0$.

The joint distribution of the length of the busy period and the number of customers served during its duration for a simple queue may be obtained from (3) as:

$$
f_{0}(t, n)=[1 / n !(n-1) !] \lambda^{n-1} \mu^{n} e^{-(\lambda+\mu) t} t^{2(n-1)} \text {. }
$$

This result agrees with that of Prabhu [3] (for $i=1$ in his result) and Takács [6].

\section{REFERENCES}

1. A. Borthakur, On Busy Period of a Bulk Queueing System with a General Rule for Bulk Service, Opsearch, Vol. 12, 1975, pp. 40-46.

2. H. Greenberg and I. Greenberg, The Number Served in a Queue, Op. Res., Vol. 14, 1966, pp. 137-44. 
3. N. U. Prabhu, Queues and Inventories, John Wiley, New York, 1965.

4. M. SCotT, Further Results for the $M / M / 1$ Queue, Cahiers du Centre d'Études de Recherche opérationnelle, Vol. 16, 1974, pp. 251-60.

5. M. Scott and M. B. Ulmer Jr., Some Results for a Simple Queue with Limited Waiting Room, Zeitchrift fur Op. Res., Vol. 16, H 5, 1972, pp. 199-204.

6. L. TAKÁCS, Introduction to the Theory of Queues, Oxford University Press, New York, 1962. 